\title{
Application of Modeling and Aversi Technique to Develop Self- Achievement Students of Vocational Schools
}

\section{Penerapan Modeling dan Teknik Aversi untuk Mengembangkan Prestasi Diri Siswa Sekolah Kejuruan}

\author{
Ida Gusti Ayu Rinjani ${ }^{\left.1^{*}\right)}$, Kadek Suranata ${ }^{2}$, I Ketut Gading ${ }^{3}$ \\ Universitas Pendidikan Ganesha \\ Kadek Suranata, e-mail: kadek.suranatta@undiksha.ac.id
}

Received July 04, 2019; Revised September 03, 2019; Accepted September 03, 2019; Published Online 03, 2019

\section{Conflict of Interest} Disclosures:

The authors declare that they have no significant competing financial, professional or personal interests that might have influenced the performance or presentation of the work described in this manuscript.

\begin{abstract}
The purpose of this study: Application of Modeling and Aversi Technique to Develop Self-Achievement Students of Vocational Schools. This research is an experimental research with pre-test / post-test control group design and design Anava A. The population is all students of class $\mathrm{X}$ at Vocational High School Bali Global Denpasar. The sampling technique is random class so that the number of samples is 103 students. Data collection techniques are observation, interview, questionnaire and document recording. The data analysis technique is Anava A and t-test formula Turkey This result is proven by the value of Fcount obtained at 47.297 and Ftable of 4.00. When compared to the value of Fcount with Ftable, it is obtained that Fcount $>$ Ftable with a significance level (p)> 0.05 which states that "there is a difference in the effectiveness of counseling behavior between modeling techniques and aversion techniques.

Keywords: Keywords: Self Achievement, Behavioral Counseling, Modeling Technique, Aversion Technique

Abstrak: Penerapan Modeling dan Teknik Aversi untuk Mengembangkan Prestasi Diri Siswa Sekolah Kejuruan. Penelitian ini merupakan penelitian eksperimen dengan pre-test/post-test control group design dan rancangan Anava A. Populasinya yaitu seluruh siswa kelas X di SMK Bali Global Denpasar. Teknik pengambilan sampel yaitu random class sehingga diketahui jumlah sampel yaitu 103 orang siswa. Teknik pengumpulan data yaitu observasi, wawancara, kuesioner dan pencatatan dokumen. Teknik analisis data yaitu Anava A dan rumus uji-t Tukey Hasil ini dibuktikan dengan nilai $F_{\text {hitung }}$ diperoleh sebesar 47,297 dan $F_{\text {tabel }}$ sebesar 4,00 Jika dibandingkan nilai $F_{\text {hitung }}$ dengan $F_{\text {tabel }}$ didapatkan bahwa $F_{\text {hitung }}>F_{\text {tabel }}$ dengan taraf signifikansi (p)>0,05 yang menyatakan bahwa "terdapat perbedaan efektivitas konseling behavior antara tehnik modeling dengan tehnik aversi .
\end{abstract}

Kata Kunci: Self-Achievement , Konseling Behavioral, Tehnik Modeling, Tehnik Aversi

How to Cite: Rinjani, I. G. A., Suranata' K., Gading' I. K. 2019. Penerapan Modeling dan Teknik Aversi untuk Mengembangkan Prestasi Diri Siswa Sekolah Kejuruan. Singaraja: Undiksha Press. Bisma The Journal of Counseling: pp. 07-17, DOI: $10.24036 / \mathrm{XX}$ 


\section{Introduction}

Berdasarkan hasil observasi peneliti mendapatkan gejala-gejala siswa yang memiliki selfachievement rendah yaitu terdapat siswa yang tidak bisa menyelesaikain sesuatu dengan baik dan akan cenderung tidak berhasil, terdapat siswa yang tidak bisa menyelesaikan sesuatu yang diikuti keahlian dan keterampilan, juga terdapat siswa yang tidak bisa menyelesaikan sesuatu yang sulit dan lebih baik dari siapapun. Karakter yang ditunjukkan oleh siswa tersebut dinamakan gejala-gejala self-achievement yang rendah.

Achievement merupakan kebutuhan untuk berprestasi meliputi menyelesaikan sesuatu dengan baik dan akan berhasil, menyelesaikan tugas dan memerlukan usaha diikuti keahlian dan keterampilan, menyelesaikan sesuatu yang penting sekali artinya, melaksanakan sesuatu pekerjaan yang sulit, memecahkan masalah yang sulit, akan mampu melakukan sesuatu yang lebih baik, menulis suatu drama, novel yang termasyur (Dharsana, 2010:1000). Dari definisi tersebut mengandung 3 indikator yaitu : (1) menyelesaikan sesuatu dengan baik dan akan berhasil, (2) menyelesaikan tugas dan memerlukan usaha diikuti keahlian dan keterampilan, (3) mampu menyelesaikan sesuatu yang penting sekali, serta lebih baik dari siapapun.

Sebagai bagian dari proses pendidikan di sekolah, pengembangan self-achievement dapat dikembangkan melalui kegiatan bimbingan konseling. Dalam hal ini, bidang keilmuan peneliti adalah bimbingan konseling sehingga penanganan ini dipilih untuk mengintervensi self-achievement. Dalam hal ini, untuk mengembangkan self-achievement siswa ini, fokusnya yaitu pada motivasi siswa yang berdampak terhadap perilakunya. Dalam melaksanakan konseling Bahavioral ini, diperlukan teknik agar tujuan konseling tercapai maksimal.

Teknik konseling Modeling merupakan bagian dari teknik konseling behavioral. Teknik ini akan memberikan informasi, pengetahuan, mensimulasi diskusi serta sebagai media mengkomunikasikan nilai atau norma yang berhubungan dengan tujuan konseling. Dalam prosesnya, teknik ini dapat berupa proses membaca, mendengarkan, maupun melihat dalam pertunjukkan, video maupun film terkait sebuah cerita yang berhubungan dengan masalah konseli.

Selain teknik konseling modeling, teknik selanjutnya yang dapat digunakan dalam konseling behavioral adalah teknik konseling Aversi.Teknik ini dimaksudkan untuk meningkatkan kepekaan konseli agar mengamati respon terhadap stimulus yang disenanginya dengan kebalikan dari stimulus tersebut. Sejalan dengan hal tersebut, Latipun (2008:143) menjelaskan bahwa teknik aversi ini diterapkan kepada konseli untuk meredakan perilaku simptomatik dengan cara menyajikan stimulus yang tidak menyenangkan (menyakitkan) sehingga perilaku yang tidak dikehendaki (simptomatik) terhambat kemunculannya berikut :

Berdasarkan latar belakang di atas, dapat diidentifikasi masalahnya adalah sebagai

Terdapat siswa cenderung gagal dalam menyelesaikan studinya.Terdapat siswa yang cenderung menunda-nunda tugas yang diberikan serta tidak memiliki bertanggung jawab untuk mengumpulkan tugas tepat pada waktunya serta Terdapat siswa yang cenderung putus asa menyelesaikan tugas yang sulit. Berdasarkan dari uraian latar belakang diatas, maka dapat dirumuskan masalahnya sebagai berikut :

1. Apakah Penerapan Konseling Behavioral teknik Modeling dalam setting Lesson Study efektif untuk mengembangkan Self-Achievement?

2. Apakah Penerapan Konseling Behavioral teknik Aversi dalam setting Lesson Study efektif untuk mengembangkan Self-Achievement?

3. Apakah terdapat perbedaan efektifitas anatara Penerapan Konseling Behavioral Teknik modeling dan teknik Aversi dalam setting Lesson Study untuk mengembangkan SelfAchievement?

\section{Method}

Penelitian eksperimen ini menggunakan rancangan pretest-posttest control group (Fraenkel \& Wallen, 2006), dengan menggunakan dua kelompok eksperimen disamping kelompok pembanding atau konstrol (waiting-tist-control) dall pengukuran temachap variabet terikat

Penerapan Modeling dan Teknik Aversi untuk Mengembangkan Prestasi Diri Siswa Sekolah

Kejuruan 
dilakukan sebelum pengkondisian atau perlakuan (pre test), dan segera setelah pengkondisian (posttest). Terhadap semua siswa di tiga kelompok dilakukan pengukuran self-achievement awal (pre test), kemudian kelompok eksperimen pertama mengikuti konseling Behavioral teknik Modeling dalam setting lesson study dan kelompok eksperimen kedua mengikuti konseling Behavioral dengan teknik Aversi melalui lesson study.

Selanjutnya diadakan Pengukuran tehadap self-Achievement kembali (post test) untuk seluruh siswa yang telah dibagi dalam ketiga kelompok tersebut.

Populasi dalam penelitian ini adalah siswa kelas X SMK TI Bali Global Denpasar

Yang Menjadi sampel dari penelitian ini adalah sejumlah tiga kelas, dua kelas sebagai kelas eksperiment kelompok 1, dan 2 dan satu kelas sebagai kelompok kontrol . Sebagai komponen pendukung kelengkapan dalam penelitian ini, digunakan buku harian yang dibuat untuk mengukur perubahan karakter siswa terkait ketiga indikator self-achievement, yang diberikan kepada siswa ketika sebelum dan sesudah tretment dilakukan dan dipantau melalui perolehan skor untuk setiap buku harian siswa.

\section{Results and Discussion}

Penelitian ini dilakukan dari bulan Maret sampai dengan bulan April tahun 2019. Adapun tujuan dari penelitian ini adalah 1) Untuk mengetahui apakah konseling Behavioral dapat diterapkan dengan teknik Modeling dalam setting Lesson Study untuk mengembangkan SelfAchievement. 2) Untuk mengetahui apakah konseling Behavioral dapat diterapkan dengan teknik Penguatan Aversi dalam setting Lesson Study untuk mengembangkan Self-Achievement 3) Untuk mengetahui bagaimana penerapan konseling Behavioral dengan teknik modeling dan penguatan Aversi dalam setting lesson study untuk mengembangkan Self-Achievment siswa kelas X SMK TI Bali Global Denpasar. Setelah penelitian selesai dilakukan, langkah selanjutnya adalah mendeskripsikan data hasil temuan berupa data observasi, wawancara, buku harian dan kuesioner

Observasi dilakukan oleh peneliti untuk mendukung ketercapaian tujuan penelitian secara maksimal. Hal ini dilakukan dengan cara mengamati secara langsung perilaku-perilaku yang nampak sesuai dengan indikator self-Achievement. Peneliti hanya memberikan tanda centang $(\sqrt{ })$ pada kolom pedoman observasi ketika perilaku yang nampak sesuai dengan indikator. Data observasi yang dideskripsikan mencakup data hasil observasi awal dan data hasil observasi akhir pada masing-masing kelompok eksperimen.

Selain melalui observasi, guna mendukung data penelitian juga dilakukan kegiatan wawancara. Adapun kutipan wawancara yang dilakukan oleh peneliti terhadap siswa yang memiliki kecenderungan self-achievement yang rendah sebagai berikut:

Tabel 1.1 Kutipan Hasil Wawancara Self-Achievement terhadap Sampel

\begin{tabular}{ll}
\multicolumn{1}{c}{ Pertanyaan } & \multicolumn{1}{c}{ Tanggapan } \\
\hline $\begin{array}{l}\text { Setelah kamu mendapatkan layanan } \\
\text { konseling mengenai self-achievement, coba } \\
\text { sekarang kamu ceritakan bagaimana } \\
\begin{array}{l}\text { aktivitasmu apakah dapat menyelesaikan } \\
\text { tugas dengan maksimal? }\end{array}\end{array}$ \\
& $\begin{array}{l}\text { Setelah mendapatkan layanan bimbingan self- } \\
\text { achievement baru saya mengerti pentingnya } \\
\text { membagi waktu agar tugas-tugas sekolah } \\
\text { dapat dikerjakan tepat pada waktunya. }\end{array}$ \\
\hline
\end{tabular}


Ohh ya, coba ceritakan bagaimana caranya membagi waktu yang baik sehingga tugastugas sekolah dapat diselesaikan?

Coba ceritakan secara garis besar seperti apa jadwal belajar yang sudah dibuat?

Nah setelah membuat jadwal belajar manfaat apa yang bisa kamu dirasakan?
Begini bu, saya membuat jadwal kegiatan sehari-hari, jadi saya mematuhui jadwal yang sudah saya buat sehingga saya dapat mengatur waktu dengan baik.
Baik bu, jadi dengan membuat jadwal kegiatan sehari-hari agar saya dapat membagi waktu kapan saya harus belajar, membatu orang tua juga waktu saya untuk bermain karena saya sangat suka bermain game online juga waktu untuk istirahan tidur malam agar saya tidak terlambat ke sekolah bu. Jadi manfaatnya saya bisa memanfaatkan waktu sebaik-baiknya untuk belajar

Sebelumnya terima kasih bu sudah memberikan layanan konseling mengenai selfachievement yang sangat bermanfaat untuk diri saya dimana sebelumnya saya menghabiskan waktu saya untuk bermain game online sehingga tugas-tugas sekolah sering saya abaikan bahkan saya tidak membuat sama sekali, Saya merasa banyak kehilangan kesempatan untuk berprestasi tetapi dengan mengikuti bimbingan klasikal, bimbingan kelompok, konseling kelompok dan konseling individu dalam setting lesson study saya baru menyadari kalau selama ini saya banyak membuang waktu saya dengan bermain game online. Kemudian setelah saya membuat jadwal kegiatan saya dapat dengan teratur melaksanakan jadwal kegiatan yang sudah saya buat. Adapun manfaat yang saya rasakan sekarang tugas-tugas sekolah dapat saya kerjakan dengan baik, sebelum ulangan saya berusaha belajar agar mendapatkan nilai yang tinggi kemudian saya selalu berlatih pelajaran matematika agar saya dapat mengerti dan memahami.

Tetapi saya masih belum yakin apakah saya bisa nantinya mengikuti pelajaran matematika karena saya tidak menyukai dengan hitung-hitungan bu?

Baiklah nak, sepertinya kamu masih ragu dengan apa yang sudah kamu laksanakan. Coba seritakan apakah dengan pesimis akan ada manfaatnva buat diri kamu?

Penerapan Modeling dan Teknik Aversi untuk Mengembangkan Prestasi Diri Siswa Sekolah 
Nah kemari kan sudah melaksanakan bimbingan konseling kelompok coba ingatingat kembali saran-saran dari temanmu!

Baiklah nak silahkan mencoba apa yang disarankan oleh teman-temannya saat konseling kelompok. Kamu harus percaya diri dan yakin bahwa kamu mampu dan bisa. Ibu ada video buat kamu judulnya Super Hero.

Setelah kamu konsultasi dengan ibu, bagaimana perasaanmu sekarang?

Baiklah nak ibu senang mendengarkan kamu sudah banyak perubahan kearah yang lebih baik jika ada masalah jangan sungkan-sungkan datang ke ruang ibu.
Saya pikir tidak ada manfaat baiknya bu, tetapi saya akan berusaha agar saya dapat mengerti pelajaran matematika tapi bagaimana caranya ya bu?

Ohh iya bu, saya baru ingat teman-teman menyarankan saya khusunya dipelajaran matematika agar saya banyak mengerjakan latihan soal-soal dan jika saya tidak mengerti saya dapat bertanya dengan teman yang lain atau saya langsung mencari guru yang bersangkutan agar bisa dijelaskan kembali dan saya nantinya dapat mengerti.

Wahh... saya terharu menonton video ini bu, dan saya merasa malu dengan diri saya sendiri. Orang yang berkebutuhan khusus saja bisa memperoleh prestasi yang luar biasa kenapa saya tidak? sementara kondisi fisik saya sempurna. Saya juga tidak mau kalah dari mereka bu saya harus menjadi orang yang berprestasi. Mulai sekarang saya tidak menyia-nyiakan waktu saya lagi saya harus giat belajar.

Baiklah bu, saya merasa lega sekarang karena tugas-tugas sekolah bisa saya kerjakan dengan maksimal, saya dapat menyelesaikan tugas yang diikuti dengan keahlian dan keterampilan, menyukai tugas yang sulit dan menantang apa lagi pelajaran matematika awalnya saya tidak mengerti dan menyukai akhirnya saya dapat mengerjakan dengan benar, prestasi saya sebelumnya dan sekarang yang sudah banyak peningkatan. Terima kasih atas bimbingannya ya bu. Jika nanti saya mengalami masalah saya akan datang ke ruangnya ibu. 
Baiklah nak selamat siang.

Terima kasih banyak bu, saya pamit karena masih ada pelajaran Bahasa Indonesia mohon ijin saya ke kelas. Selamat siang bu.

Kutipan hasil wawancara tersebut diatas, merupakan salah satu kutipan yang menunjukkan bahwa telah terjadi perubahan sikap siswa berkaitan dengan self- achievement. Secara keseluruhan, sampel pada kelompk eksperimen 1 dan eksperimen 2 mengakui telah memahami berkaitan dengan pengembangan sikap self-achievement di dalam kehidupan sehari-hari.

Buku harian juga menjadi instrument pendukung dalam pengumpulan data penelitian. Mengacu pada skor buku harian, kelompok eksperimen 1 maupun kelompok eksperimen 2 mengalami peningkatan skor setiap harinya. Berikut disajikan data buku harian kelompok eksperimen 1 dan eksperimen 2, yang dilengkapi dengan grafik.

Tabel 1.2 Data Buku Harian Kelompok Eksperimen 1

\section{Skor Buku Harian Self Achievement Dari Siswa I Putu Aby Wirayudha}

\begin{tabular}{|c|c|c|c|c|c|c|c|c|c|c|c|c|}
\hline \multirow{2}{*}{$\mathrm{NO}$} & & \multicolumn{7}{|c|}{ HARI } & \multirow{2}{*}{ Total } & \multirow{2}{*}{ Mingguan } & & \multirow[b]{2}{*}{ Bulanan } \\
\hline & & senin & selasa & rabu & kamis & jumat & sabtu & minggu & & & & \\
\hline 1 & M1 & 5 & 6 & 7 & 8 & 9 & 9 & 10 & 54 & 7.71 & Maret & 11.78 \\
\hline 2 & M2 & 10 & 12 & 14 & 18 & 18 & 19 & 20 & 111 & 15.86 & April & 48.5 \\
\hline 3 & M3 & 10 & 15 & 20 & 25 & 30 & 35 & 40 & 175 & 25.00 & & \\
\hline 4 & M4 & 46 & 47 & 48 & 49 & 50 & 51 & 52 & 343 & 49.00 & & \\
\hline 5 & M5 & 52 & 53 & 54 & 55 & 56 & 57 & 58 & 385 & 55.00 & & \\
\hline 6 & M6 & 62 & 63 & 64 & 65 & 66 & 67 & 68 & 455 & 65.00 & & \\
\hline
\end{tabular}

\section{GRAFIK HARIAN DAN MINGGUAN}

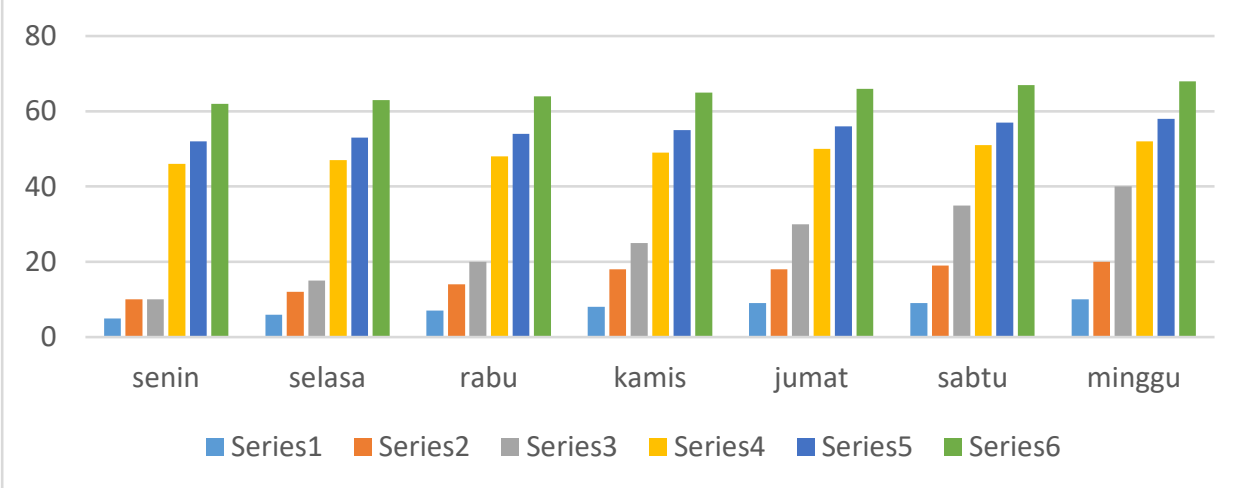

Penerapan Modeling dan Teknik Aversi untuk Mengembangkan Prestasi Diri Siswa Sekolah 

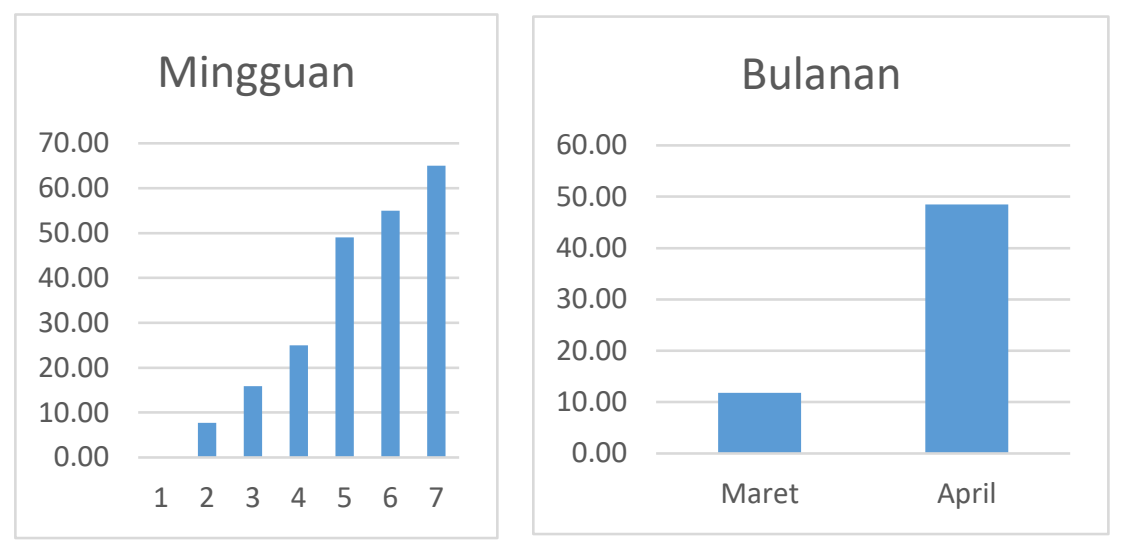

Tabel 1.3 Data Hasil Sebaran Kuesioner kelompok eksperiment 1,2, dan kelompok kontrol.

\begin{tabular}{|c|c|c|c|c|c|c|c|c|c|}
\hline $\mathbf{S}$ & & EKSP 1 & & & K EKSI & & & KONT & \\
\hline & PRE & POST & Gsn & PRE & POST & Gsn & PRE & POST & Gsn \\
\hline 1 & 81 & 130 & 0.33 & 87 & 106 & 0.13 & 77 & 79 & 0.01 \\
\hline & 107 & 136 & 0.19 & 99 & 110 & 0.07 & 60 & 67 & 0.05 \\
\hline & 105 & 137 & 0.21 & 107 & 109 & 0.01 & 67 & 68 & 0.01 \\
\hline & 122 & 136 & 0.09 & 109 & 115 & 0.04 & 66 & 69 & 0.02 \\
\hline & 130 & 137 & 0.05 & 108 & 115 & 0.05 & 108 & 109 & 0.01 \\
\hline & 105 & 119 & 0.09 & 106 & 115 & 0.06 & 118 & 120 & 0.01 \\
\hline & 110 & 135 & 0.17 & 72 & 92 & 0.13 & 75 & 76 & 0.01 \\
\hline & 82 & 128 & 0.31 & 88 & 105 & 0.11 & 118 & 119 & 0.01 \\
\hline & 103 & 127 & 0.16 & 87 & 100 & 0.09 & 107 & 108 & 0.01 \\
\hline & 116 & 130 & 0.09 & 109 & 113 & 0.03 & 77 & 78 & 001 \\
\hline 10 & 131 & 137 & $0 \Omega 4$ & 122 & 130 & 005 & 120 & 121 & $0 \Omega 1$ \\
\hline 11 & & & & & & & & & \\
\hline & 104 & 129 & 0.17 & 98 & 111 & 0.09 & 78 & 79 & 0.01 \\
\hline & 67 & 121 & 0.36 & 55 & 102 & 0.31 & 108 & 109 & 0.01 \\
\hline & 104 & 132 & 0.19 & 60 & 100 & 0.27 & 114 & 115 & 0.01 \\
\hline & 116 & 130 & 0.09 & 130 & 132 & 0.01 & 84 & 100 & 0.11 \\
\hline & 55 & 120 & 0.43 & 109 & 117 & 0.05 & 103 & 104 & 0.01 \\
\hline & 88 & 135 & 0.31 & 101 & 109 & 0.05 & 108 & 109 & 0.01 \\
\hline & 107 & 134 & 0.18 & 98 & 105 & 0.05 & 106 & 107 & 0.01 \\
\hline 10 & 104 & 123 & 0.13 & 122 & 127 & 0.03 & 88 & 89 & 0.01 \\
\hline 20 & 60 & 131 & 0.47 & 104 & 110 & 0.04 & 109 & 110 & 0.01 \\
\hline
\end{tabular}




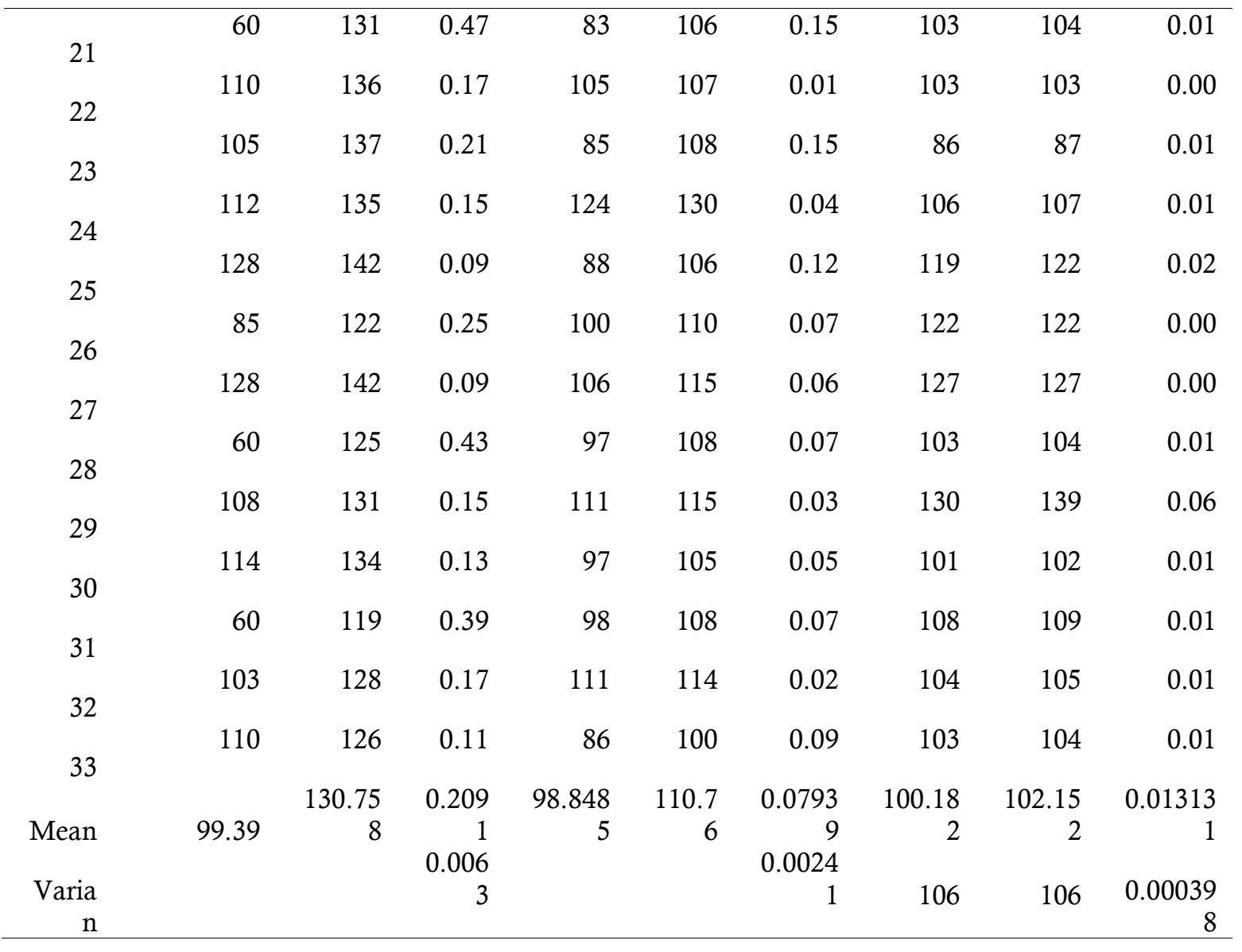

Dari tabel diatas maka dapat dijelaskan hasil dari sebaran kuesioner Self-Achievement pada kelompok eksperiment 1, kelompok eksperimen 2 dan kelompok eksperiment kontrol dapat diketahui sebagai berikut : Untuk Kelompok eksperiment 1 rata - rata skor pre test sebesar 99,39 dimana skor tersebut dikatagori tinggi dan Skor Post tesnya sebesar 130,76 dan dikategorikan sangat tinggi, sedangkan pada kelompok eksperiment 2 rata - rat skor pretest sebesar 98,84 dikategorikan tinggi, dan rata - rata skor post tes sebesar 102,152 dikatagorikan tinggi, Kemuadian skor pretest kelompok kontrol 100, dikatagorikan tinggi, dan data post test kelompok kontrol 102,15 dikatagorikan tinggi

Data rata - rata gain skor normalisasi kelompok data 1 sebesar 0,006 kelompok data 2 sebesar 0,0024 sedangkan rata - rata gain skor kelompok kontrol normalisasi sebesar 0,0004

Sebagai syarat uji hipotesis maka terlebih dahulu data yang akan diuji harus normal dan homogen yang dilakukan dengan pengukuran menggunakan bantuan SPSS 22 For Window. Uji homogenitas juga dimaksudkan untuk memperlihatkan bahwa dua atau lebih kelompok data sampel berasal dari populasi yang memiliki varians yang sama.

Tabel 1,4 Hasil Uji Homogenitas

Test of Homogeneity of Variance

\begin{tabular}{llrrrrr}
\hline \multirow{3}{*}{ Hasil post } & Levene Statistic & df1 & \multicolumn{1}{c}{ df2 } & \multicolumn{1}{c}{ Sig. } \\
& Based on Mean & 1.525 & 1 & 64 & .221 \\
& Based on Median & 1.069 & 1 & 64 & .305 \\
& Based on Median and with & 1.069 & 1 & 50.711 & .306 \\
adjusted df & 1.391 & 1 & 64 & .243 \\
\hline Based on trimmed mean & 1.39 \\
\hline
\end{tabular}

Penerapan Modeling dan Teknik Aversi untuk Mengembangkan Prestasi Diri Siswa Sekolah 
Mengingat bahwa data diketahui berkontribusi homogen maka data penelitian ini sudah memenuhi syarat analisis.

Pengujian hipotesis dalam penelitian ini menggunakan analisis varians (ANAVA) satu jalur dengan ketentuan sebagai berikut:

Dalam uji $\mathrm{F}$ ini akan menguji pengaruh utama ( Main Effect ) Bisa terjadi dua kemungkinan yaitu $\mathrm{F}_{\mathrm{A}(\mathrm{hitung})}>\mathrm{F}_{\text {tabel }}$, berarti hasil peneliytian signifikan, sedangkan bika sebaliknya maka penelitian tidak signifikan .

Bila F Signifikan harus dilanjutkan dengan uji t-scheffe, untuk membandingkan pengaruh antar metode atau tehnik.

Tabel 1.4. Hasil penghitungan dengan ANAVA satu jalur dapat dilihat dalam tabel berikut, hasil perhitungan analisi data self-achievement dengan analisis Varians satu jalur dalam penelitian ini dapat dirangkum sebagai berikut :

\begin{tabular}{|c|c|c|c|c|c|}
\hline \multirow{3}{*}{ Hasil post } & \multicolumn{3}{|c|}{ ANOVA } & & \\
\hline & & & & & \\
\hline & Sum of Squares & $\mathrm{df}$ & Mean Square & $\mathrm{F}$ & Sig. \\
\hline Between Groups & 6600.000 & 1 & 6600.000 & 109.144 & .000 \\
\hline Within Groups & 3870.121 & 64 & 60.471 & & \\
\hline Total & 10470.121 & 65 & & & \\
\hline
\end{tabular}

. Kriteria penolakan $\mathrm{H}_{\mathrm{o}}$ apabila antar tingkatan faktor pada konseling kognitif (antar kolom) nilai $F_{\text {hitung }}$ lebih besar daripada nilai $F_{\text {tabel }}\left(F_{h}>F_{t}\right)$ atau angka signifikansi lebih kecil dari 0,05.

Seperti yang disajikan pada tabel 4.2.1 nilai $\mathrm{F}_{\text {hitung }}$ diperoleh sebesar 109,144 dan $\mathrm{F}_{\text {tabel }}$ sebesar 4,00 Jika dibandingkan nilai $F_{\text {hitung }}$ dengan $F_{\text {tabel }}$ didapatkan bahwa $F_{\text {hitung }}>F_{\text {tabel }}$ dengan taraf signifikansi $(p)>0,05$ maka dapat disimpulkan bahwa hipotesis nol yang menyatakan "tidak terdapat perbedaan pengaruh konseling behavioral antara modeling dengan aversi terhadap self-achievement.", ditolak. Sebaliknya hipotesis alternatif $\left(\mathrm{H}_{1}\right)$ yang menyatakan bahwa "terdapat perbedaan efektivitas konseling behavioral antara tehnik modeling dengan tehnik aversi terhadap self-achievement.", diterima.

\section{Pengujian Hipotesis 1}

a) Hipotesis 1

$\mathrm{H}_{0}$ :Model konseling Behavioral teknik Modeling tidak efektif untuk meningkatkan selfAchievement siswa kelas X SMK TI Bali Global Denpasar

$\mathrm{H}_{\mathrm{a}}$ : Model konseling Behavioral Tehnik modeling efektif untuk meningkatkan selfAchivement siswa kelas X SMK TI Bali Global Denpasar

b). Hipotesis 2

$\mathrm{H}_{0}$ :Model konseling Behavioral Tehnik Aversi tidak efektif untuk meningkatkan selAchievement siswa kelas X SMK TI Bali Global Denpasar

$\mathrm{H}_{\mathrm{a}} \quad$ :Model konseling Behavioral Tehnik Aversi efektif untuk meningkatkan self-Achievement siswa kelas X SMK TI Bali Global Denpasar

c) Hipotesis 3

$\mathrm{H}_{0}$ : Tidak terdapat perbedaan efektivitas model konseling Behavioral teknik modeling dengan Tehnik Aversi untuk meningkatkan self-Achievement siswa kelas X SMK TI Bali Global Denpasar

$\mathrm{H}_{\mathrm{a}}$ : Terdapat perbedaan efektivitas model konseling Behavioral teknik modeling dengan Aversi ntuk meningkatkan self Achievement siswa kelas X SMK TI Bali Global Denpasar 
Pengujian hipotesis menggunakan uji t-test sampel independent agar mempermudah peneliti untuk menguji perbedaan antara siswa yang diberikan konseling Behavioral teknik modeling dengan siswa yang diberikan konseling Behavioral Tehnik Aversi Berikut rumus yang digunakan dalam menghitung uji beda, sebagai berikut :

$$
t=\frac{M \bar{X}_{1}-M \bar{X}_{2}}{\sqrt{\frac{S_{1}^{2}}{n_{1}}}+\frac{S_{2}^{2}}{n_{2}}}
$$

Berdasarkan hasil uji t untuk konseling behavioral tehnik modeling maka diperoleh data $\mathrm{t}$ hitung = 17,67, dengan $\mathrm{dk}(33+33)-2=64$ dimana $\mathrm{T}$ tabel $5 \%=2,000$ sehingga dapat disimpulkan tehnik modeling efektif terhadap peningkatan self-Achievement.

Berdasarkan hasil perhitungan uji t untuk konseling behavior teknik Aversi maka hasil uji t yaitu : 7,27 dengan $\mathrm{dk}(33+33)-2=64$ dengan $\mathrm{t}$ tabel 5\%=2,000 sehingga dapat disimpulkan bahwa konseling Behavior tehnik Aversi efektif untuk meningkatkan self Achievenet

Jadi simpulannya bahwa terdapat perbedaan perbedaan penerapan teori konseling behavior antara tehnik modeling dan tehnik aversi terhadap self-achievement Rata-rata self-achievement kelompok siswa yang mengikuti tehnik Modeling $(\bar{X}=0,2091)$ lebih tinggi daripada siswa yang mengikuti tehnik aversi. ( $\overline{\mathrm{X}}=0,0793)$.

\section{Conclusion}

Self-Achievement atau Need For Achievement merupakan kesatibiilan dalam proses pembelajaran dimana akan mendapatkan kepuasan dengan berjuang dan memenuhi level tertinggi terhadap sesuatu hal. Self-Achievement mengandung 3 indikator yaitu : (1) menyelesaikan sesuatu dengan baik dan akan berhasil, (2) menyelesaikan tugas dan memerlukan usaha diikuti keahlian dan keterampilan, (3) mampu menyelesaikan sesuatu yang penting sekali, serta lebih baik dari siapapun Terdapat perbedaan efektivitas konseling behavior tehnik modeling dengan tehnik Aversi terhadap Self-Achievement.Konseling Behavior teknik modeling lebih efektif untuk meningkatkan Self-Achievement daripada tehnik Aversi .

\section{References}

Dharsana, Ketut.(2013). Teori-Teori Konseling(Diktat).Singaraja:Jurusan Bimbingan Konseling Fakultas Ilmu Pendidikan Universitas Pendidikan Ganesha.

Dharsana, Ketut. (2014). Model-Model Teori, Teknik, Skill Bimbingan Konseling. Singaraja:Jurusan Bimbingan Konseling Fakultas Ilmu Pendidikan Universitas Pendidikan Ganesha.

Dharsana, Ketut. (2014). Dasar-dasar Bimbingan Konseling. Singaraja:Jurusan Bimbingan Konseling Fakultas Ilmu Pendidikan Universitas Pendidikan Ganesha.

Rohadian, Remy A. (1999). Kamus Dwibahasa Oxford. Jakarta: Erlangga.

Latipun. (2008). Psikologi Konseling. Malang: UMM Press

Surya Mohammad. (2003). Teori Teori Konseling. Bandung: Pustaka Bani Quraisy

Corey, Gerald. (2009). Teori dan Praktek Konseling dan Psikoterapi. Bandung: Refika Aditama

Sanyata, S. (2012). Teori dan aplikasi pendekatan behavioristik dalam konseling. Jurnal Paradigma, 14(7), 1-11.

Penerapan Modeling dan Teknik Aversi untuk Mengembangkan Prestasi Diri Siswa Sekolah

Kejuruan 
Surya, Muhamad. 1988. Dasar-dasar Konseling Pendidikan (Teori\&Konsep). Yogyakarta: Penerbit Kota Kembang.

Pihasniwati. 2008. Psikologi Konseling. Yogyakarta: Teras.

Latipun. 2008. Psikologi Konseling. Malang: UMM Press

Willis, Sofyan S. (2009). Konseling Keluarga. Bandung: Alfabeta

Lesmana, Jeanette Murad. (2008). Dasar Dasar Konseling. Jakarta: UI-Press

Purwanta, Edi. (2005). Modifikasi Perilaku Alternatif Penanganan Anak Luar Biasa. Jakarta: Departemen Pendidikan Nasional Direktorat Jendral Pendidikan Tinggi

Direktorat Pembinaan Pendidikan Tenaga Kependidikan Dan Ketenagaan Perguruan Tinggi.

Putra, I. D. G. A. P., Putri, D. A. W. M., Ps, S., \& Dharsana, I. K. (2017). Perbedaan Efektivitas Model Konseling Behavioral Teknik Modeling dengan Teknik Aversi terhadap Self Endurance Siswa Kelas X SMK Negeri 2 Singaraja. Jurnal Ilmiah Bimbingan Konseling Undiksha, 8(2).

Perangin Angin, I. A. (2014). Pengaruh Layanan Konseling Individual melalui Pendekatan Tingkah Laku Teknik Aversi untuk Meningkatkan Kedisiplinan Siswa Kelas VII SMP Raksanan Medan Ta. 2013/2014 (Doctoral dissertation, UNIMED).

Astika, I. M. A., Suarni, N. K., \& Dharsana, I. K. (2016). Efektivitas Model Konseling Behavioral Teknik Modeling dengan Teknik Shaping dalam Meningkatkan Self Achievement Siswa SMA Negeri 4 Singaraja Tahun Ajaran 2015/2016. Jurnal Ilmiah Bimbingan Konseling Undiksha, 5(2).

RIANA, I. K. J., Dharsana, I. K., \& Lestari, L. P. S. (2017). Pengaruh Teori Konseling Kognitif Behavioral dengan Teknik Modeling Basu Dewa Krisna untuk Meningkatkan Self Achievement melalui Lesson Study pada Siswa Kelas X-1 di SMA Negeri 1 Sukasada. Jurnal Ilmiah Bimbingan Konseling Undiksha, 8(2).

Article Information (Supplementary)

Conflict of Interest Disclosures:

The authors declare that they have no significant competing financial, professional or personal interests that might have influenced the performance or presentation of the work described in this manuscript.

Copyrights Holder: < Ida Gusti Ayu Rinjani, Kadek Suranata , I Ketut Gading > <2019>

First Publication Right: BISMA The Journal of Counseling

https://doi.org/10.

Open Access Article | CC-BY Creative Commons Attribution 4.0 International License.

@creative

Word Count: 3.170 